Article

\title{
Understanding Thermodynamic and Kinetic Stabilization of FeNiZr via Systematic High-Throughput In Situ XRD Analysis
}

\author{
Efraín Hernández-Rivera *(D), Sean J. Fudger, B. Chad Hornbuckle, Anthony J. Roberts \\ and Kristopher A. Darling \\ Weapons and Materials Research Directorate, US CCDC Army Research Laboratory, APG, \\ Adelphi, MD 21005, USA \\ * Correspondence: efrain.hernandez18.civ@mail.mil
}

Received: 2 March 2020; Accepted: 1 April 2020; Published: 5 April 2020

\begin{abstract}
The role of kinetically and thermodynamically driven microstructural evolution on FeNiZr was explored through in situ XRD analysis. A statistical approach based on log-likelihoods and composite link model was used to fit and extract important data from the XRD patterns. Best practices on using the statistical approach to obtained quantitative information from the XRD patterns was presented. It was shown that the alloyed powder used in the current study presents more thermodynamic stability than previously reported ball-milled powders. Based on hardness values, it was shown that mechanical strength is expected to be retained at higher processing temperatures. Lastly, a 2-dimensional heat transfer model was used to understand heat flow through the powder compacts.
\end{abstract}

Keywords: microstructural evolution; XRD; penalized likelihood analysis

\section{Introduction}

The promise of alloy design through control of a material's microstructure has led to a substantial amount of work towards developing stable bulk nanocrystalline (NC) metals over the last several decades. These NC microstructural features are desired for their known correlation to mechanical [1], radiation tolerance [2-4], and shock loading [5,6] properties. However, there has been limited success in developing stable NC alloys, with the exemption of a few notable truly thermally stable systems [7-10]. This is due to competing kinetic and thermodynamic mechanisms that arise with an increase in temperature, e.g., grain and phase evolution. Therefore, understanding these mechanisms will enable the development of truly stable NC alloys only accessible for a limited number of material systems.

Typically, the stability of these bulk NC systems is understood from a kinetic versus thermodynamic perspective. The most understood kinetic mechanism is known as Zener pinning, where secondary phases are introduced to pin grain boundary motion [11-13]. One of the limitations of this mechanism is the need to have efficient spacing between pinning features, otherwise unconstrained grain growth will result [14]. From a thermodynamic stabilization standpoint, solute drag has been suggested as a mechanism to enhance NC stability by arresting growth kinetics [15]. Solute drag occurs when solute atoms segregate to interfaces enveloping grain boundaries and lowering their chemical potential, which inhibits their motion [16,17]. In fact, solute drag can be considered a crossover mechanism where the solute presence on the grain boundary affects the mobility as well as reduces the thermodynamic driving force. This inherently means that solutes in grain boundaries lead to an increase of grain boundary mobility activation energy, while at the same time decreasing the excess grain boundary free energy. Koch et al. suggested that Zener pinning is more stable for NC metals 
$(<100 \mathrm{~nm})$ at high homologous temperatures [18]. Moreover, thermodynamic stabilization has gained attention due to the intrinsic applicability to alloy design $[19,20]$. Nonetheless, it is often difficult to determine which stabilizing mechanism dominates for a particular material system $[19,21]$.

A common technique for producing NC metals is mechanical alloying (MA), which blends different powders by cold-welding and fracturing [22]. This technique can have the added benefit of producing high purity alloyed powders from elemental powders. Therefore, it has been widely used in the development of NC metals. Iron-based alloys are of special interest because of the wide range of applications for steel alloys, which yields many opportunities for developing alternative materials. Some systems that have received notable attention include $\mathrm{Fe}-\mathrm{Al}$ [23,24], $\mathrm{Fe}-\mathrm{Cr}$ [25], $\mathrm{Fe}-\mathrm{Cu}$ [26,27], $\mathrm{Fe}-\mathrm{Ni}$ [28], and Fe-Zr [29], amongst others. The latter two, where Ni and $\mathrm{Zr}$ lead to a decrease in the phase transition temperature and grain boundary stabilization, respectively, motivated development of $\mathrm{Fe}_{1-x-y} \mathrm{Ni}_{x} \mathrm{Zr}_{y}$ alloys [4,30-33], which result in a decrease in phase transition temperature and grain boundary stabilization from the $\mathrm{Ni}$ and $\mathrm{Zr}$ additions, respectively. Alloying with $\mathrm{Zr}$ increases the likelihood of oxides forming due to its affinity for oxygen, which results in an oxide dispersion strengthened (ODS) alloy [34]. This special alloy subclass has been widely studied for nuclear fission reactor structural applications due to their stability at higher temperatures $[4,35]$. Kotan et al. showed that this alloy is kinetically stable to temperatures up to $700{ }^{\circ} \mathrm{C}$. However, it has been shown that the ferrite-to-austenite transitions $(\alpha \rightarrow \gamma)$ can be measured through XRD at lower temperatures $\left(\sim 630-650^{\circ} \mathrm{C}\right)[31,33]$.

Recent work exploring the competing mechanisms between kinetically and thermodynamically stabilized NC alloys has focused on understanding and harnessing the phase transition kinetics to enable true stability [33,36-38]. Huang et al. showcased the importance of this interplay through a detailed study on the $\mathrm{Fe}_{91} \mathrm{Ni}_{8} \mathrm{Zr}_{1} \alpha \rightarrow \gamma$ where they observe that grain growth is constrained by the reverse austenite $(\gamma)$ transformation. To add to this understanding between phase transformation and grain growth in $\mathrm{Fe}_{91} \mathrm{Ni}_{8} \mathrm{Zr}_{1}$, a detailed in situ evolution study across multiple isothermal conditions is performed. One of the more interesting features of this alloy is that it undergoes polymorphic transformation at temperatures similar to where unconstrained grain growth is observed. This makes it a great candidate for studying the interplay between kinetically and thermodynamically driven microstructural evolution [38]. To better understand the relationship between phase transformation and grain growth in $\mathrm{Fe}_{91} \mathrm{Ni}_{8} \mathrm{Zr}_{1}$, high-throughput (HiTp) in situ X-ray diffractometry (XRD) is used to characterize the evolving microstructure. A penalized likelihood fitting procedure is implemented to approximate the observed data [39]. This statistical approach is used to analyze microstructural evolution, e.g., grain size and phase amounts. Lastly, a 2D thermal transport simulation is presented to comment on the expected thermal state during the XRD measurements.

The main objective of this work is to demonstrate the applicability of a statistical based fitting algorithm to quantify the microstructural and thermodynamic evolution of the FeNiZr alloy. While common-practice methods like the Rietveld refinement are great at quantifying XRD patterns, they require a priori knowledge of the observed microstructure, and can be cumbersome when analyzing a large data set. The proposed methodology is able to fit XRD patterns without a priori knowledge of the underlying microstructure. Furthermore, it can also be easily used to extract important microstructural features like average grain size and phase concentration. Also, due to this flexibility, it can easily be incorporated into HiTp frameworks to analyze large datasets.

\section{Experimental Procedure}

\subsection{Mechanical Alloying}

The $\mathrm{Fe}_{91} \mathrm{Ni}_{8} \mathrm{Zr}_{1}$ (at. \%) ternary alloy was investigated to fully characterize the thermodynamic stability of the NC Fe-rich alloys. The NC powders were alloyed by mixing $800 \mathrm{~g}$ of high purity elemental powders ( $\mathrm{Fe}-99.9 \%$ from American Elements, Ni-99.9\% from American Elements and $\mathrm{Zr}-99.5 \%$ from Materion). The initial elemental powders are stored and loaded into the milling vessel 
in an Ar filled glovebox to minimize exposure to oxygen ( $\leq 20 \mathrm{ppm})$. The MA was performed in a ZOZ CM08 rotary ball mill (Zoz GmbH, Wenden, Germany) with a 10:1 ball to powder mass ratio of $1 / 4$ " stainless steel balls. A positive pressure of Ar is maintained within the milling vessel during the milling process again to minimize exposure to oxygen. Alloying of the powder was for $30 \mathrm{~h}$ at sub-zero temperatures, which limits the amount of cold-welding and increases alloying through fracture. This resulted in a homogeneous unagglomerated alloyed NC powder with particle sizes between 5-100 $\mu \mathrm{m}$. The milled powder was then transferred to air tight containers, sealed, and stored within the glovebox to further limit exposure to air.

\subsection{In Situ XRD Characterization}

Microstructural evolution was monitored at elevated temperatures through in situ XRD analysis performed with an Anton Paar HTK 2000 N fitted with a PW3376/00 Co LFF DK184436 tube. This source allows for optimization of the peak-to-noise ratio inherent from Fe absorption of $\mathrm{Cu}$ radiation. A thin layer $(\sim 1 \mathrm{~mm})$ of alloyed powder was placed on top of a Pt heat strip holder, which was then aligned to the diffractometer optical axis. The chamber was depressurized to approximately $1 \times 10^{-5}$ Torr and filled with forming gas $(97 \% \mathrm{Ar} / 3 \% \mathrm{H})$ to prevent oxidation of the samples during the in situ measurements. Samples were then resistively heated to the target temperature with the maximum heating rate $\left(350-400^{\circ} \mathrm{C} / \mathrm{min}\right)$ and held at temperature for $60 \mathrm{~min}$. Diffraction patterns of a limited diffraction range (48-55 deg) were collected every minute for an hour, with a collection time of approximately $20 \mathrm{~s}$, quantifying the quasi-instantaneous structure. This scanning frequency results in HiTp microstructural information. This limited diffraction range was chosen because it is known to contain the bcc (110) and fcc (111) diffraction peaks, which enable observation of the phase transitioning. This procedure was repeated for $700,800,900$, and $1000{ }^{\circ} \mathrm{C}$ isothermal conditions. After cooldown, a final scan at room temperature (RT) was performed to characterize the resulting microstructure for each condition. The XRD patterns were analyzed by a penalized likelihood smoothing approach [39], and these patterns were used to calculate grain size via the Scherrer method [40]. The diffraction peak full-width-half-max (FWHM) was used to calculate the grain size since it is less sensitive to background removal than the integral breadth approach. Lastly, instrumental broadening was corrected by applying the same analysis to the $\mathrm{LaB}_{6}$ standard.

\subsection{Hardness Measurements}

Vickers hardness measurements were performed on $3 \mathrm{~mm}$ diameter compacts of the various heat treated conditions. The compacts were made by pressing $\sim 0.1 \mathrm{~g}$ of powder to $3 \mathrm{GPa}$ within a $3 \mathrm{~mm}$ diameter WC die set. These compacts were then annealed in a tube furnace under a forming gas to prevent oxidation at the same temperatures as those used for the XRD studies. Samples were annealed for 20,40, and $60 \mathrm{~min}$ and then were allowed to cool to room temperature. The furnace heating rate was approximately $110{ }^{\circ} \mathrm{C} / \mathrm{min}$. Hardness measurements were taken using a Wilson Tukon 1202 micro-hardness tester equipped with a Vickers diamond-pyramid indenter from the polished surfaces of the various heat treated specimens.

\section{Results and Discussion}

\subsection{XRD Characterization Methodology}

To fully characterize the microstructural evolution, in situ XRD patterns were collected during short dwell times. One of the limitations of analyzing patterns obtained within short collection times at elevated temperatures is that the resulting patterns tend to be noise prone. The noise arises from the limited signal count and the vibrational frequency of the excited atomic structure. Typical approaches to characterizing XRD patterns, to include the Rietveld refinement [41], assume the XRD patterns follow a symmetric probability distribution, e.g., Gaussian distribution. Due to the complex kinetic and thermodynamic evolution captured in this work, the resulting patterns tend to be asymmetric. 
Furthermore, due to the HiTp data collection process, a large amount of data is collected. Therefore, developing a systematic approach to analyze the data is of utmost importance. In order to best overcome these limitations, a penalized log-likelihood (PL) scheme developed by de Rooi et al. [39] was adopted. The PL method specifies a set of statistical parameters that maximize the likelihood that the observed data is most probable, as predicted from a statistical model, and has the form

$$
L\left(\mu_{i} \mid y_{i}\right)=y_{i} \log \mu_{i}-\mu_{i}-\log y_{i} !
$$

where $y_{i}$ is the XRD pattern intensity at a $2 \theta$ Bragg diffraction angle and $\mu_{i}$ is the intensity estimator. Additionally, de Rooi et al. also presented a technique based on the composite link model, which allows for the decomposition of the approximated pattern to be separated into $\mathrm{K} \alpha_{1}$ and $\mathrm{K} \alpha_{2}$ components. This decomposition enables $\mathrm{K} \alpha_{2}$ removal for quantitative grain size calculations. This approach has been successfully implemented to XRD patterns from bulk samples, thin films and standards [39], nanotubes/wires [42] and single crystal topological crystalline insulators [43]. While traditional approaches like Rietveld refinement do not require the XRD patterns to be smoothed or decomposed into $\mathrm{K} \alpha_{1}$ and $\mathrm{K} \alpha_{2}$ components for qualitative analysis, these techniques require a priori knowledge of the expected microstructure. The PL method is "material agnostic" in the sense that it will be able to analyze the patterns without a presumed atomic structure.

Figure 1a shows an example of PL smoothing and is compared to a pseudo-Voigt fit, which shows these fits to be of comparable performance. An important intrinsic feature about the PL method is that you can obtain a confidence interval, shown as the green bands on Figure 1a, yielding a statistical measure of the goodness of fit (see Supplemental Information). Since the smoothing method employed is based on the use of B-splines, care must be taken to choose the proper number of spline segments $\left(n_{s}\right)$. Figure $1 \mathrm{~b}$ shows the resulting fits for three $n_{s}$ values. If too few segments are used, the splines are unable to properly approximate the XRD pattern. However, including too many segments will lead to an over fitting of the curve. To determine the optimal number of segments, the mean square error (MSE) and Pearson-correlation were calculated as a function of $n_{s}$ (see Supplemental Information Figure S1). It can be seen that for $n_{s}=40$ both these metrics begin to plateau, meaning that little information is gained from increasing $n_{s}$. It is shown that the PL method tends to perform badly when fitting at the diffraction angle extremes, especially when the data is overfit (i.e., $n_{s}=200$ ). This is likely a result of trying to extrapolate an overfit B-spline of a noise prone signal.
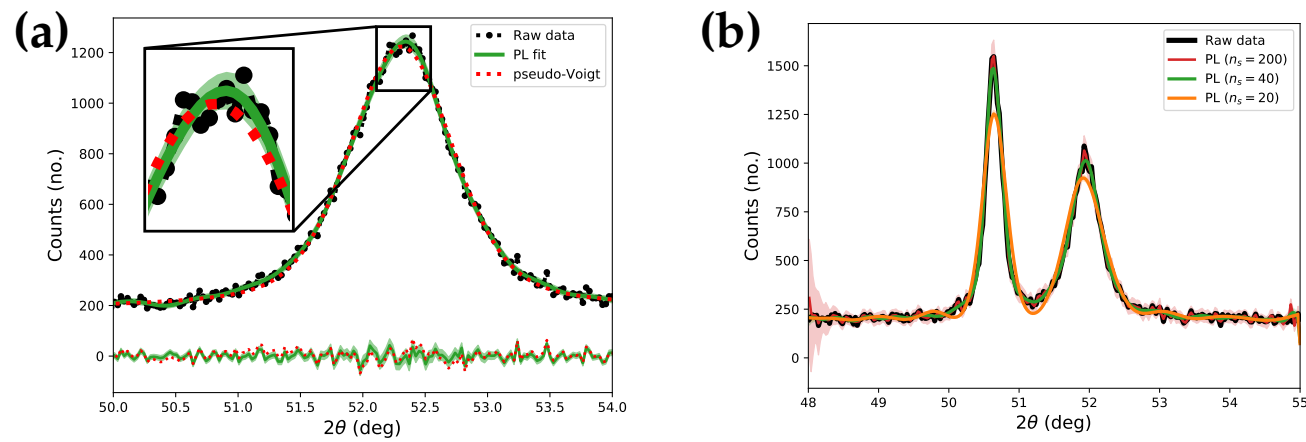

Figure 1. Example of the smoothing and fitting schemes. (a) Shows the differences between a traditional pseudo-Voigt and the PL smoothing for the as milled powder. The error for each fit is shown below the pattern. The green bands correspond to the PL 95\% confidence interval. (b) Shows the influence of the number of spline segments on the goodness of fit. Too many segments lead to over fitting, while too few does not capture the proper pattern shape. Note that for $n_{s}=200$, the $95 \%$ confidence interval quickly grows towards the beginning of the pattern. 


\subsection{Microstructure Phase Evolution}

The concurrent microstructural changes were examined by XRD for four isothermal conditions. To be able to perform such short collection times, the diffraction range was limited to capture the (110) $\alpha$ and (111) $\gamma$ diffraction planes. Figure 2a shows the pre and post-annealed XRD patterns with the resulting (110) $\alpha$ peak at RT. The preannealed patterns (dashed curves) clearly show broad (110) $\alpha$ peaks (at $2 \theta \sim 52.35$ degs), indicative of nanocrystalline bcc. Post-annealed patterns (solid curves) show that $700-900{ }^{\circ} \mathrm{C}$ retain some level of nanocrystallinity,

$$
\bar{r}_{\alpha}^{10-60}(\mathrm{~nm})= \begin{cases}21.7, & T=700{ }^{\circ} \mathrm{C} \\ 25.2, & T=800{ }^{\circ} \mathrm{C} \\ 42.3, & T=900{ }^{\circ} \mathrm{C}\end{cases}
$$

Furthermore, there's a peak shift to lower angles, which suggests a change in lattice constant due to solute diffusion out of solution. Contrary to Kotan et al., a $\gamma$ peak was not detected at $700{ }^{\circ} \mathrm{C}$ after holding for an hour (see Figure $2 b$ ), who reported the presence of the peak at $650{ }^{\circ} \mathrm{C}$. In fact, even at $800^{\circ} \mathrm{C}$ only a relatively small peak is detected. Interestingly, Huang et al. also observed the early onset of the phase transition [33,36]. Kotan et al. also report that $\alpha$ grain growth stagnates to a grain size of $\sim 50 \mathrm{~nm}$ at a critical temperature of $T_{0} \sim 710^{\circ} \mathrm{C}$ [33], about twice as large as those observed in the present study. This suggests that the powder tested in this work is more thermally stable than previously reported alloys of nominally similar chemical composition. This could be due to differences in the milling procedures, which might lead to better (more uniform) mixing of our alloyed powders. Another possible explanation is the high heating rate $\left(>350^{\circ} \mathrm{C} / \mathrm{min}\right)$. Huang et al. showed that by increasing the heating rate from $20 \mathrm{~K} / \mathrm{min}$ to $40 \mathrm{~K} / \mathrm{min}$ the amount of austenite present is substantially lower across multiple annealing conditions [36]. Therefore, our much higher heating rate could have resulted in a lower amount of austenite formation, which effectively retards grain growth. If powders are not properly mixed, the presence of Ni-depleted regions could result in earlier $\alpha \rightarrow \gamma$ transition. Figure 2c shows a representative set of XRD patterns collected at several times for the $900{ }^{\circ} \mathrm{C}$ condition. It is clear that the $\gamma$ phase nucleates at the onset of the XRD measurements. The $\gamma$ peak narrows quickly, and remains consistently narrow for the duration of the experiment. It should be noted that the measured $\gamma$ grain sizes are at the resolution limit.
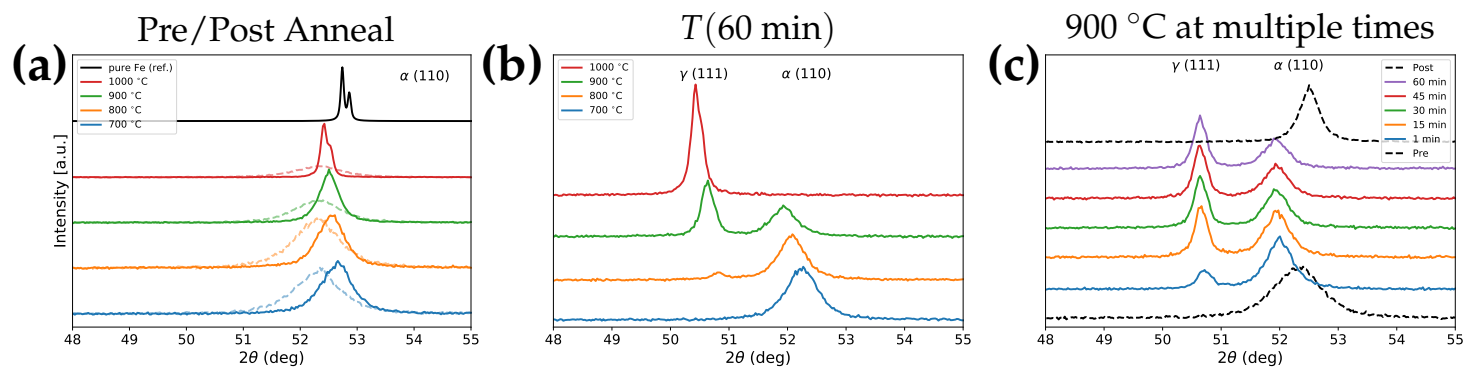

Figure 2. In situ XRD measurements were performed at different anneals, showcasing the instantaneous microstructural state. (a) pre (dashed) and post (solid) annealed alloys at RT showing the presence of $\alpha \mathrm{Fe}_{91} \mathrm{Ni}_{8} \mathrm{Zr}_{1}$ (bulk Fe reference was simulated with VESTA [44]), (b) after 60 min holds at the corresponding temperatures, and (c) $900{ }^{\circ} \mathrm{C}$ anneal illustrating the nucleation and evolution of the $\gamma$ phase.

To better understand the interplay between kinetic and thermodynamic stability, the XRD patterns were used to approximate the relative phase concentrations. An advantage of the PL method is that there is no need for a priori knowledge of the possible phases present. While techniques like Rietveld refinement yield a concentration measure from the fitting procedure, no equivalent measures emerge 
from the PL method. Therefore, three methods were tested to approximate the relative concentration, and are expressed as

$$
C_{b c c} \equiv \frac{X_{b c c}}{X_{b c c}+X_{f c c}}=\left\{\begin{array}{l}
\frac{\max \left(\mu_{b c c}\right)}{\max \left(\mu_{b c c}\right)+\max \left(\mu_{f c c}\right)} \\
\frac{\max \left(\hat{y}_{1, b c c}\right)}{\max \left(\hat{y}_{1, b c c}\right)+\max \left(\hat{y}_{1, f c c}\right)} \\
\frac{\int \hat{y}_{1, b c c} d(2 \theta)}{\int \hat{y}_{1, b c c} d(2 \theta)+\int \hat{y}_{1, f c c} d(2 \theta)}
\end{array}\right.
$$

where $X$ is the $p$ phase fraction and $\hat{y}_{1}$ is the $K \alpha_{1}$ component of the estimated XRD pattern. The first two variants consider the corresponding phase maximum intensity from the estimated XRD and $\mathrm{K} \alpha_{1}$ patterns, respectively. While the last equation is similar to the technique known as integral breadth method. It should be noted that calculations yield a qualitative measure of the phase change.

The three methods were tested on the $900{ }^{\circ} \mathrm{C}$ condition since both phases were observed throughout the complete hold, see Figure $3 a$. It is shown that Equation $(3 a, 3 b)$ follow a similar trend, with the former overestimating the amount of retained ferrite. While the use of $\mu$ pattern as opposed to $\hat{y}$ pattern seems to lead to an overestimation, the confidence intervals suggest that these are statistically equivalent. In contrast, the "integral breadth method" largely overestimates the amount of retained ferrite. This overestimation is likely due to the difficulty in consistent background removal of low intensity peaks. Furthermore, it leads to a larger uncertainty level, illustrated by the large shaded region. Therefore, Equation (3a) is used to calculate the amount of retained ferrite for all isothermal conditions, shown in Figure $3 \mathrm{~b}$ and summarized for 5 min intervals in Table 1.

Table 1. Summary of the calculated $\alpha$ concentration as a function of time.

\begin{tabular}{lcccc}
\hline Time $[\mathrm{min}]$ & $\mathbf{C}\left(\mathbf{7 0 0}{ }^{\circ} \mathbf{C}\right)$ & $\mathbf{C}\left(\mathbf{8 0 0}{ }^{\circ} \mathbf{C}\right)$ & $\mathbf{C}\left(\mathbf{9 0 0}{ }^{\circ} \mathbf{C}\right)$ & $\mathbf{C}\left(\mathbf{1 0 0 0}{ }^{\circ} \mathbf{C}\right)$ \\
\hline 1 & 1.000 & 1.000 & 0.700 & 0.199 \\
5 & 1.000 & 1.000 & 0.559 & 0.110 \\
10 & 1.000 & 0.848 & 0.524 & 0.096 \\
15 & 1.000 & 0.850 & 0.485 & 0.000 \\
20 & 1.000 & 0.835 & 0.460 & 0.000 \\
25 & 1.000 & 0.825 & 0.453 & 0.000 \\
30 & 1.000 & 0.833 & 0.438 & 0.000 \\
35 & 1.000 & 0.812 & 0.421 & 0.000 \\
40 & 1.000 & 0.807 & 0.408 & 0.000 \\
45 & 1.000 & 0.804 & 0.401 & 0.000 \\
50 & 1.000 & 0.802 & 0.395 & 0.000 \\
55 & 1.000 & 0.797 & 0.389 & 0.000 \\
60 & 1.000 & 0.796 & 0.384 & 0.000 \\
\hline
\end{tabular}




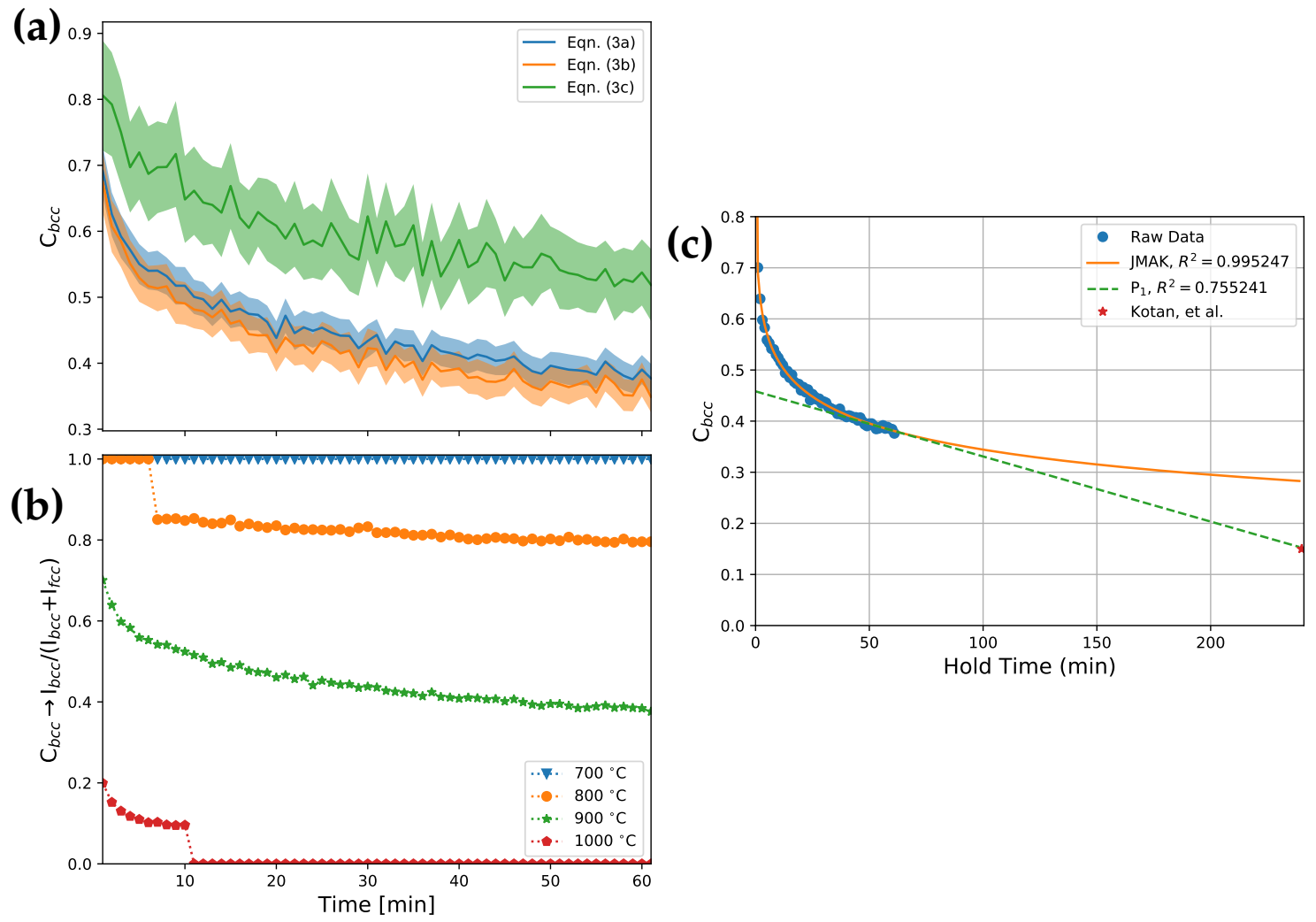

Figure 3. Approximation of the retained $\alpha$ phase at different hold times. (a) different methods were tested to determine which method is more reliable, $(\mathbf{b})$ the resulting phase evolution at the different isothermal conditions, and (c) fit to the $900{ }^{\circ} \mathrm{C}$ estimated phase evolution, which is compared to the result by Kotan et al. The linear fit was performed using the last $17 \mathrm{~min}$ of the current data.

\subsection{Concurrent Grain Growth and Mechanical Property's Implication}

The XRD patterns were analyzed through the Scherrer method to calculate the average grain size for the different anneal cases, shown in Figure 4a. The blue shaded region represents the grain sizes over the resolution limit for our instrumental setup. Furthermore, it must be noted that a $n_{s}=40$ was observed to under fit the grain sizes. This is due to the slightly under estimated peak intensity $(\mu)$, which results in a smaller half maximum $\mathrm{K} \alpha_{1}$ intensity. Hence, the $n_{s}$ parameter was increased to 60 and 80 for $\alpha$ and $\gamma$ grains, respectively, which resulted in better grain growth trends. It can be seen that initially there is thermally activated grain growth from an initial size of $10.54 \pm 0.27 \mathrm{~nm}$ (black line), followed by a stabilization of the $\alpha$ growth. Considering the XRD patterns between 10-60 min anneals, the average $\alpha$ grain size was determined to be

$$
\bar{r}_{\alpha}^{10-60}(n m)= \begin{cases}20.5 \pm 0.4, & T=700^{\circ} \mathrm{C} \\ 27.3 \pm 1.1, & T=800^{\circ} \mathrm{C} \\ 29.9 \pm 1.5, & T=900^{\circ} \mathrm{C}\end{cases}
$$

Comparing these to the calculated post-anneal grain size (Equation (2)), it is shown that there's non-negligible grain growth for the $900{ }^{\circ} \mathrm{C}$ case. The microstructure remained stable at $700{ }^{\circ} \mathrm{C}$, showing no further grain growth through the remainder of the experiment. For 800 and $900{ }^{\circ} \mathrm{C}$ anneals, the $\alpha$ phase grains grew slightly more, but remained stable as well. However, the $\gamma$ phase was shown to undergo substantial grain growth. In fact, the 900 and $1000{ }^{\circ} \mathrm{C}$ anneals show grain sizes that are at/or beyond the resolution limit. It should be noted that due to low signal-to-noise ratio in the early stages at 800 and $1000{ }^{\circ} \mathrm{C}$, the calculated grain sizes for $\gamma$ and $\alpha$, respectively, are not completely reliable. 
(a)

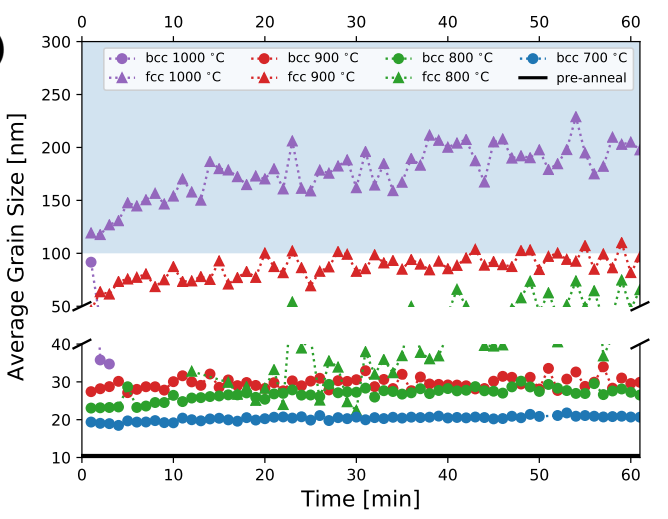

(b)

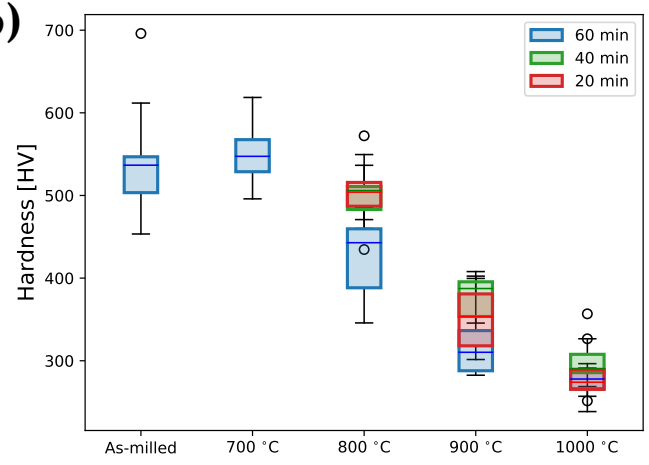

Figure 4. Annealing at temperatures over $700{ }^{\circ} \mathrm{C}$ lead to microstructural changes and subsequent mechanical properties decline. (a) shows grain growth curves for both phases (where detected) at the different anneals, and (b) shows boxplots for hardness taken at different anneal conditions.

Figure $4 \mathrm{~b}$ shows hardness measurements for all anneal conditions after 60 min holds. Furthermore, hardness for the 800,900 and $1000{ }^{\circ} \mathrm{C}$ after 20 and 40 min holds are shown. For comparison, hardness values for the as-milled powders are shown as well. For $700{ }^{\circ} \mathrm{C}$, hardness values were only after a 60 min anneal because the XRD analysis did not show any significant microstructural changes as a function of anneal time. While the grain size is slightly larger after a $700{ }^{\circ} \mathrm{C}$ anneal than the as-milled powder (see Equations (2) and (4)), a small increase in average hardness is observed. This increase is likely due to dissolution of the $\mathrm{Zr}$ remaining in solution from the as-milled condition, resulting in the nucleation of more $\mathrm{Zr}$-oxide precipitates. For the $800{ }^{\circ} \mathrm{C}$ anneal, the hardness values for 20 and $40 \mathrm{~min}$ anneals overlap, while a substantial drop is noticed for the $60 \mathrm{~min}$ hold. This is likely due to grain boundaries becoming unpinned by the oxide precipitates, leading to grain growth and reducing the Hall-Petch effect. Lastly, the 900 and $1000{ }^{\circ} \mathrm{C}$ anneals show a large drop in hardness when compared to the as-milled powder. The $900{ }^{\circ} \mathrm{C}$ anneal shows a gradual decrease in hardness with increase in hold time. However, hardness values are statistically undistinguishable at the three holds. For the $1000{ }^{\circ} \mathrm{C}$ anneal, the hardness decreases to approximately $281.6 \pm 30.2 \mathrm{HV}$ after $20 \mathrm{~min}$, and remains statistically unchanged for the other hold times. This correlates to the measured XRD which showed that the alloy fully undergoes the $\alpha \rightarrow \gamma$ transformation after $\sim 10 \mathrm{~min}$.

\section{Conclusions}

The relationship between kinetic and thermodynamic stability of the $\mathrm{Fe}_{91} \mathrm{Ni}_{8} \mathrm{Zr}_{1}$ alloy was explored through HiTp in situ XRD across multiple anneals. In order to efficiently fit and analyze the large data set, a PL method was employed to quantify microstructural changes as measured from the XRD patterns. A systematic approach was formulated and best practices in employing the PL method were discussed. The proposed methodology is not only able to fit XRD patterns with a priori knowledge of the underlying microstructure, and it can easily be used to extract important microstructural features like average grain size and phase concentration. The $\alpha \rightarrow \gamma$ transition was not observed until higher temperatures, suggesting that the alloy presented here was comparatively more thermodynamically stable than those previously reported. Furthermore, $\alpha$ was shown to be relatively stable at isotherms up to $900^{\circ} \mathrm{C}$, although asymptotically decreasing. Changes in mechanical properties were examined via hardness measurements, which show that mechanical integrity is maintained for the $700{ }^{\circ} \mathrm{C}$. For higher anneals, mechanical integrity gradually deteriorates until plateauing to bulk properties as nanocrystallinity is lost. It is believed that the unique MA applied synthesized superior alloyed powders.

Supplementary Materials: The following are available online at http:/ /www.mdpi.com/2075-4701/10/4/482/s1, Figures S1, S2 and S3. 
Author Contributions: E.H.R.-conceptualization, formal analysis, methodology, software, visualization, writing — original draft, and writing-review \& editing; S.J.F.-conceptualization, investigation, methodology, and writing - review \& editing; B.C.H.-investigation, and writing-review \& editing; A.J.R.-investigation; and K.A.D.-conceptualization, funding acquisition, methodology, and writing-review \& editing. All authors have read and agreed to the published version of the manuscript.

Funding: This research received no external funding.

Acknowledgments: E.H.R. would like to thank Paul Eilers for helpful discussions regarding the derivation of the confidence interval for likelihood models.

Conflicts of Interest: The authors declare no conflict of interest.

\section{References}

1. Meyers, M.A.; Mishra, A.; Benson, D.J. Mechanical properties of nanocrystalline materials. Prog. Mater. Sci. 2006, 51, 427-556. [CrossRef]

2. Odette, G.; Alinger, M.; Wirth, B. Recent developments in irradiation-resistant steels. Annu. Rev. Mater. Res. 2008, 38, 471-503. [CrossRef]

3. Beyerlein, I.; Caro, A.; Demkowicz, M.; Mara, N.; Misra, A.; Uberuaga, B. Radiation damage tolerant nanomaterials. Mater. Today 2013, 16, 443-449. [CrossRef]

4. Darling, K.; Kapoor, M.; Kotan, H.; Hornbuckle, B.; Walck, S.; Thompson, G.; Tschopp, M.; Kecskes, L. Structure and mechanical properties of Fe-Ni-Zr oxide-dispersion-strengthened (ODS) alloys. J. Nucl. Mater. 2015, 467, 205-213. [CrossRef]

5. Bringa, E.M.; Caro, A.; Wang, Y.; Victoria, M.; McNaney, J.M.; Remington, B.A.; Smith, R.F.; Torralva, B.R.; Van Swygenhoven, H. Ultrahigh strength in nanocrystalline materials under shock loading. Science 2005, 309, 1838-1841. [CrossRef]

6. Frontán, J.; Zhang, Y.; Dao, M.; Lu, J.; Gálvez, F.; Jérusalem, A. Ballistic performance of nanocrystalline and nanotwinned ultrafine crystal steel. Acta Mater. 2012, 60, 1353-1367. [CrossRef]

7. Detor, A.J.; Schuh, C.A. Tailoring and patterning the grain size of nanocrystalline alloys. Acta Mater. 2007, 55, 371-379. [CrossRef]

8. Chookajorn, T.; Murdoch, H.A.; Schuh, C.A. Design of stable nanocrystalline alloys. Science 2012, 337, 951-954. [CrossRef]

9. Khalajhedayati, A.; Rupert, T.J. High-temperature stability and grain boundary complexion formation in a nanocrystalline Cu-Zr alloy. Jom 2015, 67, 2788-2801. [CrossRef]

10. Darling, K.; Rajagopalan, M.; Komarasamy, M.; Bhatia, M.; Hornbuckle, B.; Mishra, R.; Solanki, K. Extreme creep resistance in a microstructurally stable nanocrystalline alloy. Nature 2016, 537, 378-381. [CrossRef]

11. Smith, C.S. Grains, phases, and interfaces: An interpretation of microstructure. Met. Technol. 1948, 15, 1-37.

12. Doherty, R.; Hughes, D.; Humphreys, F.; Jonas, J.J.; Jensen, D.J.; Kassner, M.; King, W.; McNelley, T.; McQueen, H.; Rollett, A. Current issues in recrystallization: A review. Mater. Sci. Eng. A 1997, 238, 219-274. [CrossRef]

13. PA, M.; Ferry, M.; Chandra, T. Five decades of the Zener equation. ISIJ Int. 1998, 38, 913-924.

14. Humphreys, F.; Hatherly, M. (Eds.) Recrystallization and Related Annealing Phenomena, 2nd ed.; Elsevier: Oxford, UK, 2004; pp. 557-615.

15. Cahn, J.W. The impurity-drag effect in grain boundary motion. Acta Metall. 1962, 10, 789-798. [CrossRef]

16. Weissmüller, J. Alloy effects in nanostructures. Nanostructured Mater. 1993, 3, 261-272. [CrossRef]

17. Kirchheim, R. Grain coarsening inhibited by solute segregation. Acta Mater. 2002, 50, 413-419. [CrossRef]

18. Koch, C.C.; Scattergood, R.O.; Saber, M.; Kotan, H. High temperature stabilization of nanocrystalline grain size: Thermodynamic versus kinetic strategies. J. Mater. Res. 2013, 28, 1785-1791. [CrossRef]

19. Saber, M.; Koch, C.C.; Scattergood, R.O. Thermodynamic grain size stabilization models: An overview. Mater. Res. Lett. 2015, 3, 65-75. [CrossRef]

20. Kalidindi, A.R.; Chookajorn, T.; Schuh, C.A. Nanocrystalline materials at equilibrium: A thermodynamic review. Jom 2015, 67, 2834-2843. [CrossRef]

21. Peng, H.; Huang, L.; Liu, F. A thermo-kinetic correlation for grain growth in nanocrystalline alloys. Mater. Lett. 2018, 219, 276-279. [CrossRef]

22. Suryanarayana, C. Mechanical alloying and milling. Prog. Mater. Sci. 2001, 46, 1-184. [CrossRef] 
23. Grosdidier, T.; Ji, G.; Launois, S. Processing dense hetero-nanostructured metallic materials by spark plasma sintering. Scr. Mater. 2007, 57, 525-528. [CrossRef]

24. Sasaki, T.; Ohkubo, T.; Hono, K. Microstructure and mechanical properties of bulk nanocrystalline Al-Fe alloy processed by mechanical alloying and spark plasma sintering. Acta Mater. 2009, 57, 3529-3538. [CrossRef]

25. Saber, M.; Kotan, H.; Koch, C.C.; Scattergood, R.O. Thermal stability of nanocrystalline Fe-Cr alloys with Zr additions. Mater. Sci. Eng. A 2012, 556, 664-670. [CrossRef]

26. Wille, C.; Al-Kassab, T.; Schmidt, M.; Choi, P.P.; Kwon, Y.S. Homogeneity of mechanically alloyed nano-crystalline Fe-Cu-powders. Int. J. Mater. Res. 2008, 99, 541-547. [CrossRef]

27. Mojtahedi, M.; Goodarzi, M.; Aboutalebi, M.; Ghaffari, M.; Soleimanian, V. Investigation on the formation of $\mathrm{Cu}-\mathrm{Fe}$ nano crystalline super-saturated solid solution developed by mechanical alloying. J. Alloy. Compd. 2013, 550, 380-388. [CrossRef]

28. Hong, L.; Fultz, B. Two-phase coexistence in Fe-Ni alloys synthesized by ball milling. J. Appl. Phys. 1996, 79, 3946-3955. [CrossRef]

29. Darling, K.; VanLeeuwen, B.; Koch, C.; Scattergood, R. Thermal stability of nanocrystalline Fe-Zr alloys. Mater. Sci. Eng. A 2010, 527, 3572-3580. [CrossRef]

30. Kotan, H.; Darling, K.A.; Saber, M.; Koch, C.C.; Scattergood, R.O. Effect of zirconium on grain growth and mechanical properties of a ball-milled nanocrystalline FeNi alloy. J. Alloy. Compd. 2013, 551, 621-629. [CrossRef]

31. Kotan, H.; Darling, K.A.; Saber, M.; Scattergood, R.O.; Koch, C.C. An in situ experimental study of grain growth in a nanocrystalline $\mathrm{Fe}_{91} \mathrm{Ni}_{8} \mathrm{Zr}_{1}$ alloy. J. Mater. Sci. 2013, 48, 2251-2257. [CrossRef]

32. Kotan, H.; Darling, K.A.; Scattergood, R.O.; Koch, C.C. Influence of Zr and nano-Y2O3 additions on thermal stability and improved hardness in mechanically alloyed Fe base ferritic alloys. J. Alloy. Compd. 2014, 615, 1013-1018. [CrossRef]

33. Huang, L.; Lin, W.; Lin, B.; Liu, F. Exploring the concurrence of phase transition and grain growth in nanostructured alloy. Acta Mater. 2016, 118, 306-316. [CrossRef]

34. Hu, Y.J.; Li, J.; Darling, K.A.; Wang, W.Y.; VanLeeuwen, B.K.; Liu, X.L.; Kecskes, L.J.; Dickey, E.C.; Liu, Z.K. Nano-sized superlattice clusters created by oxygen ordering in mechanically alloyed Fe alloys. Sci. Rep. 2015, 5, 11772. [CrossRef] [PubMed]

35. Ukai, S.; Fujiwara, M. Perspective of ODS alloys application in nuclear environments. J. Nucl. Mater. 2002, 307, 749-757. [CrossRef]

36. Huang, L.; Lin, W.; Wang, K.; Song, S.; Guo, C.; Chen, Y.; Li, Y.; Liu, F. Grain boundary-constrained reverse austenite transformation in nanostructured Fe alloy: Model and application. Acta Mater. 2018, 154, 56-70. [CrossRef]

37. Amram, D.; Schuh, C.A. Interplay between thermodynamic and kinetic stabilization mechanisms in nanocrystalline Fe-Mg alloys. Acta Mater. 2018, 144, 447-458. [CrossRef]

38. Hu, Y.J.; Wang, Y.; Wang, W.Y.; Darling, K.A.; Kecskes, L.J.; Liu, Z.K. Solute effects on the $\Sigma 3$ 111 [11-0] tilt grain boundary in BCC Fe: Grain boundary segregation, stability, and embrittlement. Comput. Mater. Sci. 2020, 171, 109271. [CrossRef]

39. de Rooi, J.J.; van der Pers, N.M.; Hendrikx, R.W.; Delhez, R.; Böttger, A.J.; Eilers, P.H. Smoothing of $\mathrm{X}$-ray diffraction data and $\mathrm{K} \alpha 2$ elimination using penalized likelihood and the composite link model. J. Appl. Crystallogr. 2014, 47, 852-860. [CrossRef]

40. Langford, J.I.; Wilson, A. Scherrer after sixty years: A survey and some new results in the determination of crystallite size. J. Appl. Crystallogr. 1978, 11, 102-113. [CrossRef]

41. Rietveld, H. A profile refinement method for nuclear and magnetic structures. J. Appl. Crystallogr. 1969, 2, 65-71. [CrossRef]

42. Varlec, A.; Arčon, D.; Škapin, S.D.; Remškar, M. Oxygen deficiency in MoO3 polycrystalline nanowires and nanotubes. Mater. Chem. Phys. 2016, 170, 154-161. [CrossRef]

43. Zhong, R.; Schneeloch, J.; Liu, T.; Camino, F.; Tranquada, J.; Gu, G. Superconductivity induced by In substitution into the topological crystalline insulator $\mathrm{Pb}_{0.5} \mathrm{Sn}_{0.5}$ Te. Phys. Rev. B 2014, 90, 020505. [CrossRef]

44. Momma, K.; Izumi, F. VESTA 3 for three-dimensional visualization of crystal, volumetric and morphology data. J. Appl. Crystallogr. 2011, 44, 1272-1276. [CrossRef]

(C) 2020 by the authors. Licensee MDPI, Basel, Switzerland. This article is an open access article distributed under the terms and conditions of the Creative Commons Attribution (CC BY) license (http:/ / creativecommons.org/licenses/by/4.0/). 